\title{
Local or Global? Approaches for New Product Development in Low Income Countries
}

\author{
Timothy Whitehead ${ }^{\mathrm{a} *}$, Mark Evans ${ }^{\mathrm{b}}$ and Guy A Bingham ${ }^{\mathrm{c}}$ \\ ${ }^{a}$ Engineering and Applied Science, Aston University, Birmingham, UK \\ ${ }^{b}$ Loughborough Design School, Loughborough University, Loughborough, UK \\ ${ }^{c}$ Arts, Design and Humanities, De Montfort University, Leicester, UK \\ *Dr Timothy Whitehead, Engineering and Applied Science, Aston University, \\ Birmingham, B4 7ET, UK, t.whitehead@aston.ac.uk
}

\section{Bio statements}

Dr Timothy Whitehead

ORCID ID: https://orcid.org/0000-0001-8751-1484

Dr Timothy Whitehead is a Lecturer in Product Design with a research interest in developing tools and approaches to improve the design of products distributed in low income countries. Timothy has worked on a number of projects funded through the Global Challenges Research Fund which utilise design methods and new technology to improve the livelihood of those living on less than $\$ 1$ a day.

\section{Dr Mark Evans}

ORCID ID: https://orcid.org/0000-0002-1378-8998

Dr Mark Evans is a Reader in Industrial Design with research interests in design practice that support the development of tools/resources and explore its use during data collection. He has a background as a practitioner for clients that include British Airways, Unilever and Honda. A diverse range of funding sources has generated over 100 academic publications with appointments that include membership of the AHRC Peer Review 
College; visiting professor at Rhode Island School of Design; editorial board member for two academic journals; and International Scholar at MIT. Recent outputs include the Design Practice Research Case Studies website for PhDs in which the researcher employed practice to support data collection (9500 views/downloads); the iD Cards design communication tool in collaboration with the IDSA (5000 fold-out cards distributed to members/13000 app downloads); a three month exhibition at the National Centre for Craft and Design for an EPSRC project to explore the commercial opportunities for 3D concrete printing (10159 visitors, 98000 video views); and a design tool/video/website from an AHRC project in which industrial design was used to identify export product opportunities manufactured using indigenous materials/crafts in emerging economies. In 2016 he was the first international member to receive the IDSA Educator of the Year Award.

\section{Prof Guy Bingham}

ORCID ID: https://orcid.org/0000-0002-6971-033X

Prof Guy Bingham is Chair of Design and Director of the Design Unit at De Montfort University - an independent design-research organisation that offers a range of designbased research and New Product Development opportunities. His current research focuses on design, design practice and the design opportunities/applications of Additive Manufacturing and 3D printing. A Peer Review College member for the AHRC and EPSRC with a portfolio of over 50 publications from a range of funding sources, including; ERSRC, AHRC, Innovate UK and Research England. 


\title{
Local or Global? Approaches for New Product Development in Low- Income Countries
}

\begin{abstract}
To increase opportunity and quality of life for people living in poverty, governments and non-government organisations (NGOs) sell products to lowincome countries. These are typically products that can make fundamental changes to the quality of life such as; water filters and solar lighting. However, there has been limited research to support the new product development (NPD) process for this unique category of products which has led to instances of suboptimal solutions. This paper explores the nature of design and manufacture in these countries, and the impact of local and global approaches has on product development. Empirical data has been generated through interviews with ten senior staff from NGOs; 10 product users, and observations of the NPD process in Myanmar. The findings identify that the development of products undertaken in developed countries could provide can provide high-quality solutions, but at the expense of user insight and local capacity building.
\end{abstract}

Keywords: designing for development; new product development; low-income countries; industrial design.

\section{Introduction}

The design and development of products with the capacity to make a fundamental contribution to the quality of life for people living in poverty has typically been advocated by engineering designers who seek to find practical solutions to meet the needs of users. These products usually include water filters, latrine pits and solarpowered lighting. In the last few years, industrial designers have become increasingly involved in this arena, bringing methods such as user-centred design, participatory design and design for $\mathrm{X}$ into the design process (Castillo et al., 2012). This is accompanied by the adoption of business models and approaches based on bottom of the pyramid economics (Prahalad, 2006) which advocate the selling products to users through micro-loans and grants. The combination of these factors has led to a change in 
the operating environment for industrial designers and charities which has resulted in a need to more fully understand the requirements for New Product Development in LowIncome Countries (LICs).

In this paper, the process of New Product Development (NPD) for essential products is explored and defined as; the activity of developing physical products for a target market, which typically involves various stakeholders working together to create products which enhance the human experience (Cagan and Vogel, 2002). These activities start with market perception and opportunity and end with the sale of a product (Oevermann 2008). In acknowledging a variety of approaches to NPD, this study has identified 'Global NPD' as a process in which the product are designed and manufactured outside of the country of distribution, whereas 'Local NPD' relates to this activity being undertaken inside of the country of distribution. Although, is it common practice in developed countries to rely on a global approach to NPD this study investigates the challenges and opportunities faced in low-income countries, which have a variety of different methods. To better understand the impact of these approaches, this study examines the user perception of contrasting design types and uses this data to inform researchers, designers and the broader academic profession about the advantage and disadvantages of NPD location. The following research questions were established;

(1) How are products designed and manufactured in/for low-income countries?

(2) Does the location of the NPD process affect industrial design practice?

(3) What is the user perception of the products distributed?

(4) What can industrial designers learn from this?

To fully contextualise the research, data collection was undertaken in Myanmar (formerly Burma). Myanmar is one of the least developed countries in Southeast Asia 
and the worst performer in terms of economic and social progress. According to the World Bank, $32.1 \%$ of the population live in poverty, which equates to 15.8 million people. These poor households have few working-age adults and a high number of dependents (Grundy et al, 2014). Most of the poor are in the agriculture sector as casual labours or small hold farmers. (World Bank, 2017). To understand how products are designed manufactured and distributed, a design-focused social enterprise in Myanmar was contacted. A social enterprise is a business that operates to tackle social problems or improve communities, making money from selling goods and services in the open market and reinvesting profit in the business or local community. The social enterprise had been operating in Myanmar since 2004 and distributes a range of household products that generate income for the rural poor, such as agriculture irrigation pumps, water storage and LED solar lights. They have built up a network of stakeholders to facilitate access to $80 \%$ of the population. When choosing the social enterprise, it was important they had a mix of locally designed products as well as globally designed and imported products.

\section{Poverty, International Development and Industrial Design}

Poverty can be defined as "the pronounced deprivation in wellbeing, comprising many dimensions, including the inability to acquire basic goods and necessities for survival with dignity" (World Bank, 2011). Typically, the poor suffer from hunger, deprivation and powerlessness (Hamner, Narayan, \& Donaldson, 2013). Currently, the World Bank estimates 1.4bn people are living in poverty. Although the root causes are involved, one of the primary causes is that for the last 42 years per capita growth rate in developing nations has remained close to zero, while developed countries experienced good levels of growth with newly industrialised countries seeing a high level of growth 
(Easterly, 2007). As a result, developing countries can be caught in a trap as they do not have the ability, or resources, to increase growth and invest in a more secure future by themselves (Sachs 2005). Consequently, many large aid projects have been devised to increase growth which would, in turn, improve the quality of life for a significant percentage of a population (Easterly, 2007). Since the 1960s, $\$ 2.3$ trillion has been spent on foreign aid which has resulted in limited impact (Sachs, 2005). This has led to charities and other non-government organisations donating products with the potential to make a fundamental increase in quality of life; typically these products include; water filters, solar lights and cookstoves. These products are generally lower cost and less sophisticated than highly capital-intensive products and technologies commonly seen in the developed world, being referred to as employing 'intermediate' or 'appropriate technology’ approach (Schumacher, 1973). Historically, many organisations were established to deliver these intermediate and appropriate technologies to LIEs, including Practical Action (formerly ITDG) (practicalaction.org), the German Appropriate Technology Exchange (eldis.org) and the United States Appropriate Technology International (ncat.org). In recent years many of these organisations have declined in size and struggled to maintain financial support. For example, the United States Congress reduced its funding to Appropriate Technology International (now Enterprise Works Worldwide/VITA) due to the lack of positive results (Polak \& Warwick, 2013). The reduction in funding has led to a shift in thinking and many approaches to product distribution in international development are being built on business principles and market forces as opposed to philanthropic donation.

Changes to these approaches have also coincided with the maturing of the profession of industrial design, which once focused on the form and manufacture of physical products. Now industrial design is often seen to employ its methods to shape 
strategy and re-frame complex problems (Conkin, 2005), and business direction see for example the work of consultancies such as; IDEO and Frog Design which describe themselves as 'design innovation providers', utilising tools and methods such as Design Thinking. This shift in focus and renewed awareness of challenges faced in international development has led several design consultancies to focus on projects and business strategy for LIC, examples include; IDEO.org (ideo.org) and ThinkPlace in Kenya (thinkplaceglobal.com). These design consultancies not only focus on the physical product but also broader issues that involve a cyclical process of user engagement and prototyping, to address a broad range of design challenges, including those related to services and system design. These approaches have been identified as having the capacity to contribute to the resolution of significant global challenges, such as poverty and sustainability (Kandachar 2012). However, despite these changes which encourage designers to work on socially beneficial projects to date, few methods and case studies have been created to support the physical design activity and facilitate product development, which can directly improve quality of life for those living in poverty. The critical resources that are currently available include Design for Micro-Enterprise (DfME) (Austin-Breneman \& Yang, 2013); Design for Extreme affordability (MIT, 2013); and Designing for the base of the pyramid (Diehl \& Christiaans, 2007; Castillo, Diehl, \& Brezet, 2012). Each of these approaches provides a useful starting point for generating design insights but does little to help the designer to understand methods of NPD and if a local or global approach is most suitable. Therefore this study aims to generate knowledge and understanding of the issues arising in low-income countries when the design is carried out both locally and globally. The specific objectives for the study were to: 
(1) Identify both locally and globally designed products which are distributed to people living on low income in Myanmar.

(2) Interview industrial designers $(n=3)$ to better understand the new product development approach taken for global new product development

(3) Interview industrial designers $(n=10)$ to better understand the new product development approach taken for local new product development

(4) Interview Myanmar families who own both local and globally designed products for 5 years and understand their perceptions

(5) Identify the impact this knowledge has on future industrial designers.

\section{Method}

The study adopted a flexible, qualitative approach and was conducted in three phases consisting of interviews and observations with those involved in Local and Global NPD. These results were then compared with interviews and observations from families who owned both a locally and globally produced product, for five years.

The first phase was undertaken to identify the nature of local NPD and was achieved through interviews with the senior design team, manufacturing team leaders and distribution team of the social enterprise. Ten interviews were conducted, each lasting between 30 and 40 minutes. The nature of the organisation meant that there was a mixture of nationalities and not all employees spoke English. As a result, several interviews were carried out with a translator and notes taken during the interview. Observations of the local NPD process were conducted within the organisation and recorded through note taking and photography. Particular attention was paid to the manufacturing and assembly of components and how the designers interacted with 
locals from Myanmar during the NPD process. The second set of interviews were conducted with global NPD teams which involved interviews with product designers and managers from NGOs in the USA. Three interviews were conducted which lasted between 40-50 minutes each. The nature of the location of Global NPD teams meant that these interviews were conducted in English via Skype. In both cases the interviews followed the same semi-structured approach and were transcribed in English.

The final part of the study involved interviews with ten local families, each of which owned both a global and local designed product sold by the social enterprise in Myanmar. Interviews were conducted at the family homes, which were all within 2 hours drive of Yangon. A semi-structured approach was adopted and each interview lasted approximately one hour and included a tour of the household/farm and a demonstration of the product, which had typically been owned for five years. It was found during this data collection translation played a significant factor as few of the families spoke English. An independent translator was employed for the research, instead of one from the social enterprise that arranged each of the meetings, to avoid bias. The translation was conducted in situ and transcribed using audio recordings, detailed notes and photographs. The hospitable nature of the Burmese people meant that any form of social interaction in the home included an invitation to sit, drink tea and eat a selection of local food. It was evident that this hospitality was an essential part of the data collection and helped to build a rapport with participants and put them at ease before beginning the formal interview (Hennink, 2007). The combination of these three methods enabled triangulation of the results and allowed the researcher to compare the impact of Local and Global NPD on the creation of products, importantly with a focus on the users desires and opinion of the products. 
Once the data had was collected, it was analysed using thematic analysis with an open coding approach (Robson, 2011). This consists of identifying codes and grouping them into themes which then form the basis for interpretation (Gibbs, 2008). The nature of the research meant that the codes were created entirely from the data through an exploratory process (Tesch, 1990).

\section{Challenges conducting field research}

There were several challenges faced conducting this study, which are worth noting. Firstly, it was necessary that the participants did not perceive the researcher had links with the organisation that had arranged the interviews as this may have distorted the responses. Adopting an approach similar to that published in IDEOs Human Centred Design field manual (IDEO, 2018) provided a useful starting point in which the interviewer did not wear branded clothing and selected an independent translator. It was found that the translator sometimes struggled to clearly convey meaning and we found that our taxi driver was very helpful in assisting, likely due to his experience talking with tourists. During the interviews it was also important to maintain eye contact with the participants and focus on the translator, as this can be seen as rude (see figure 1). It was also noted that building a rapport was crucial and a large amount of time was spent socialising, before we discussed the products. However, it was observed that the translator enjoyed talking with the participants and sometimes failed to provide a comprehensive synopsis. For example, during the beginning of the study, the translator would speak to the users for approximately five minutes and then provided a translation of "he said yes". This was addressed after the first two instances to ensure that the data was accurately recorded, however, it is common when researching in this context that translations are not always clear. 


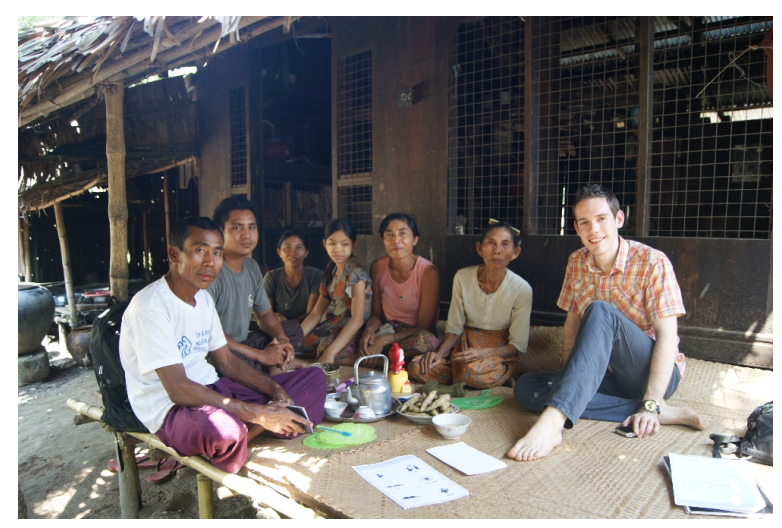

Figure 1. Household interviews

\section{Results}

The reporting of the results has been divided into three sections:

(1) Local NPD (water pump) - Design, Manufacture and Product Distribution

(2) Global NPD (D-Light) - Design, Manufacture and Product Distribution

(3) User perceptions of local and global designed products

\section{New Product Development Process}

A typical NPD process consists of the following steps, (i) the design team generate a project brief formulated using a combination of market research and business planning. (ii) The team employ a user-centred design approach to problem-solving, utilising design thinking methods and spending a large proportion of their time with users. (iii) Prototypes are designed, developed and tested with users to ensure they meet local needs. (vi) On completion of the design, the team prepare for local manufacture.

\section{Local Design and Manufacture}

Evidence from the interviews revealed that although supporting the local economy by designing and manufacturing locally was seen as positive; several design challenges were created, such as; limited access to skilled labour and the availability of 
high-quality production equipment. It was observed that the design team often spent up to $50 \%$ of their time supporting manufacturers while attempting to improve production quality. This was because the local industrial zone consisted primarily of simple huts that accommodated injection moulders, press machine operators and welders (see Figure 2). Consequently, the level of quality and consistency of parts represents a continual challenge, with many of the manufacturers relying on manual processes, meaning that the quality of component could be dependent on which machine operator was working on a particular day.
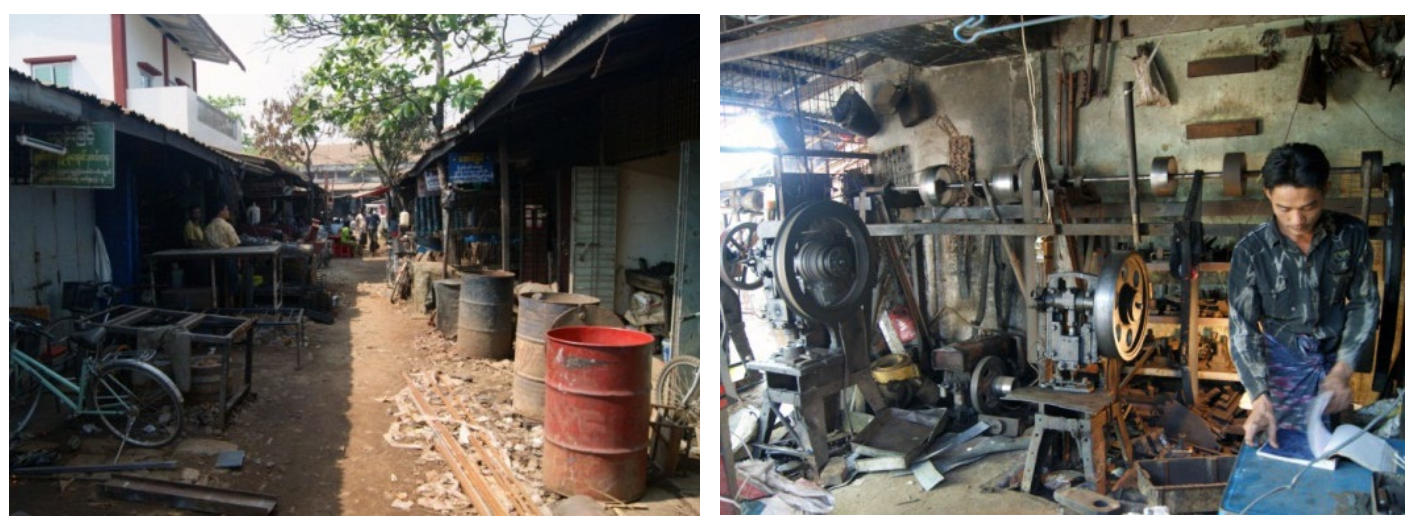

Figure 2. Industrial Zone in Yangon

This lack of manufacturing skill was primarily due to insufficient levels of education and long-term investment in the country which is typical of LICs. The effect of this had a direct impact on the capabilities of a local NPD process as a considerable amount of time was spent educating the local workforce or trying to obtain and specify materials used in production. An example of this was given by one of the industrial designers who stated that when asking a manufacturer which plastic he had used in an injection moulded component, he responded "battery covers". This meant that the designers were unable to know the properties of the plastic component and if it would be suitable for their design. Figure 3, shows a typical injection moulded shop with product sorting. 

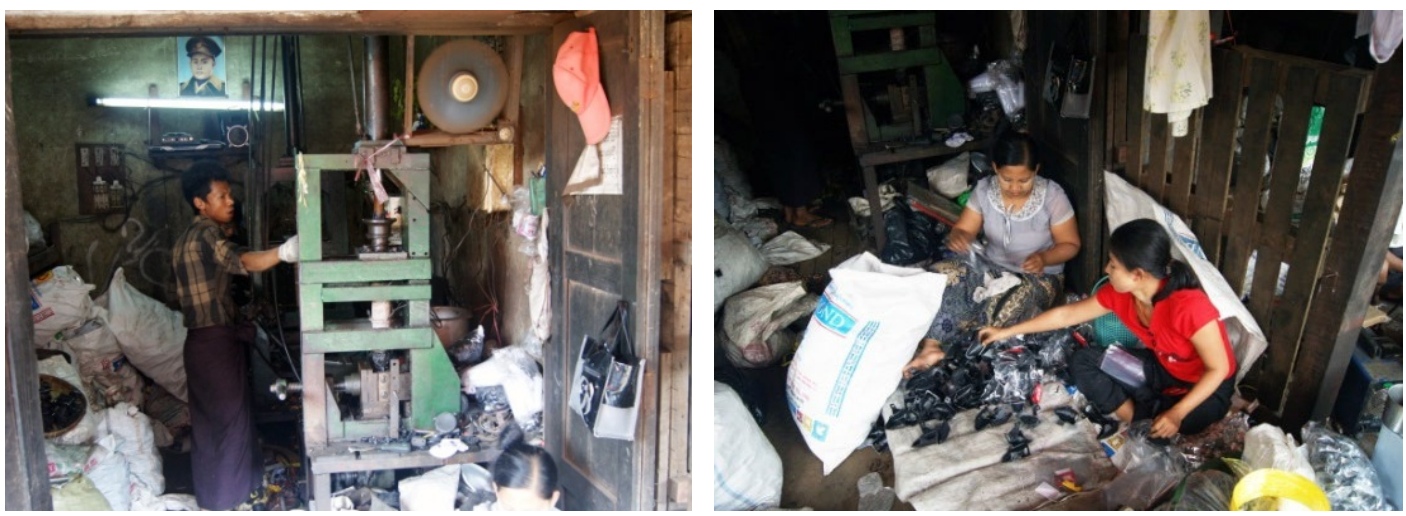

Figure 3. Injection Moulder in the Industrial Zone, Yangon

This presented several challenges for the Social Enterprise which delayed the development and deployment of new products, and can be summed up in the following quote;

"Manufacturing in Myanmar is very basic and limited. When we started, we used to show our drawings to the manufacturers, and they would not understand them. They had never seen an engineering drawing before and didn't know how to follow/read it. I think it is both a blessing and a curse manufacturing here." (Interview with S3-01)

Once the components have been produced, the products were assembled using local labour. Western-educated engineers worked alongside local operatives to provide a level of on-going education to support the process of product assembly. Simple jigs, mounts and a form of quality control had been implemented to ensure that products were manufactured to the correct size and tolerance. The designers reported the introduction of quality control was also a novel concept and one which local people needed educating in; Figure 4 shows the production line and product assembly. 

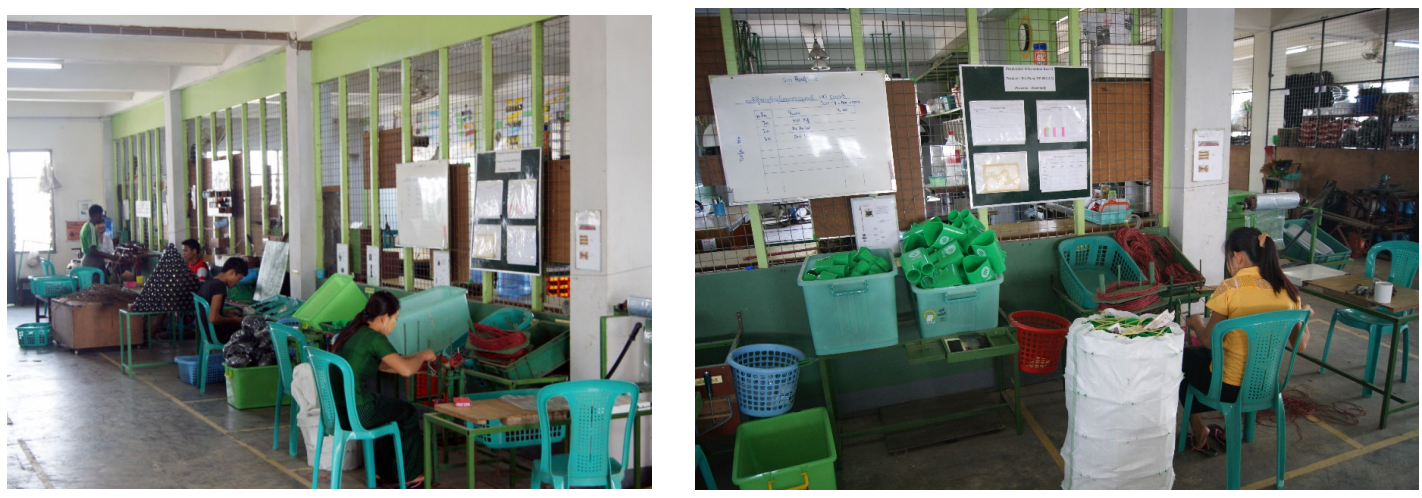

Figure 4. Assembly line, Yangon

Once assembled (see figure 5) products were sold throughout Myanmar using a network of approximately 130 sales agents who distributed both locally and globally designed products.

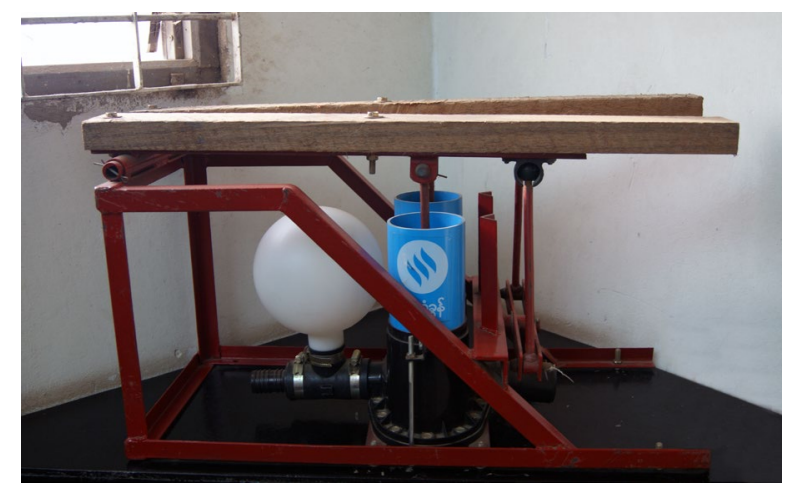

Figure 5. Assembled water pump

\section{Global - Design and Manufacture}

To attain a comprehensive understanding of the differences in approaches of local and global design and manufacture the D-Light was analysed. The design of the light was undertaken in the USA which adopted a user-centred approach thereby enabling the design team to spend a significant amount of time conducting field research. This involved visiting users and entering into discussions to more fully understand the context and environment that the product was to be designed for. According to the founder, this was because current products were not suitable for the environment and they wanted to create a product which "truly met user needs". As a result, many field 
visits were carried out to establish design requirements where it was discovered that product users did not typically receive high-quality products. Therefore, this product development process aimed to create a product that users would be proud to own. Once these user needs had been established and the product prototyped in the USA, the design team were split up with some working in India to establish a market and the rest working with Chinese manufacturers to create products which were "great value for money, excellent quality and low cost". According to the company, these demanding requirements would have been hard to achieve if the design, development and manufacture were carried out in an LIC. The consequences of this approach enabled the design and manufacture of a product that was of high quality, reduced cost and ensured that production standards were maintained. The result was that the LED light was manufactured to be robust and sealed to prevent dust or other substances getting to the electronics. These products were imported to Myanmar and distributed by the sales team alongside the locally designed products. Each of the LED lights (see Figure 6) was sold with a two-year warranty, meaning that if the product failed it could be returned to the sales agent.

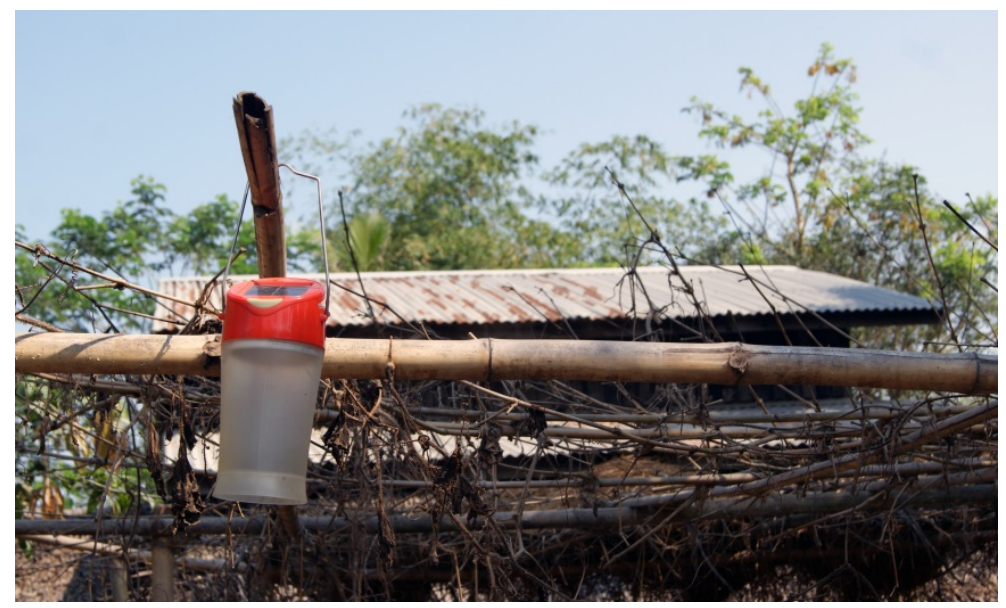

Figure 6. Globally manufactured solar-powered lantern - D-Light 
For both local and global products agents sold them into local communities.

These sellers were typically farmers who bought the product, found it to be beneficial and subsequently become a product reseller. The agents worked on commission within a dedicated sales area, and approximately $70 \%$ of all products were sold on finance, with repayment plans ranging from five months to two years.

\section{User perceptions of local and global products}

To assess the impact and user perception of these contrasting approaches to NPD, ten interviews were undertaken with families who owned both a Local (water pump, see figure 7 in use.) and Global (solar LED light, see figure 6) for between one and five years. These were undertaken to identify features which were considered as being desirable/necessary/essential in design. The results were compared and contrasted with those the designers and design teams.

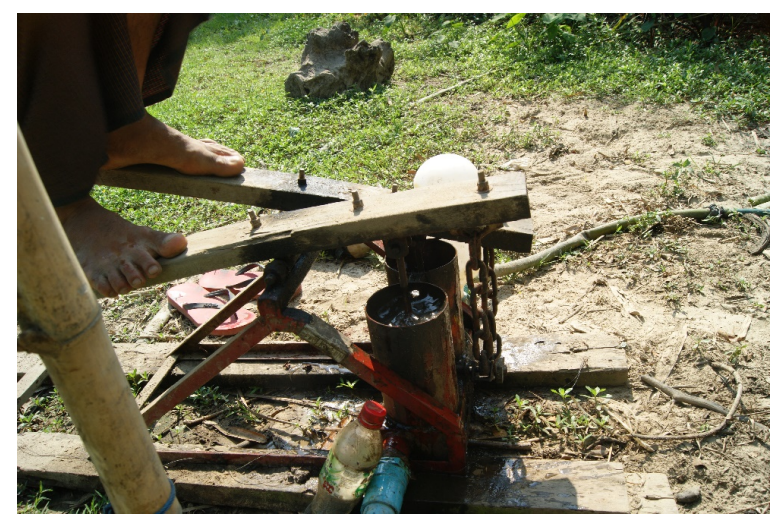

Figure 7. Locally manufactured water pump

It was identified that a critical attribute for product uptake was the ability to save the user time and reduce manual labour, as many of the processes were previously carried out without any technical assistance. Seven out of ten participants described that 
ease of use was the most critical element a product could have. For example, one interviewee stated that before having a water pump they had to carry an engine pump across the road and connect it up which was a time-consuming task, and the pump was expensive to run. Another stated that with the water pump they could now have "water when I need it" and a third responded that having these products "enables us to have more time for other activities so we can make more money”. It was therefore evident that users found considerable benefit from owning these essential products, but when considering ease of use and time saving, it did not seem to matter if the design was locally or globally produced.

However, the quality of the components used in production was highlighted as a differentiation between local and globally produced products. Locally produced products often broke easily or wore out prematurely (see Figure 8). One interviewee commented that the locally manufactured pump had "lots of problems", stating that the washers were breaking and leaking; burrs were left on the inside of a piston-cylinder after manufacture, and the pump became significantly less efficient over time. As a result of these defects, products are often neglected and left abandoned and participants thought they were not good value for money. However, when discussing the globally manufactured LED light, participants did not report any problems; instead, users stated it was a good and robust design that was well-made. In fact, during the interviews it was observed that users liked to wrap the product in newspaper during the day, stating that this prevented the plastic becoming scratched and "spoiling the product". Five of the interviewees also commented that they did not worry about the durability of the light as if there was a problem they knew they could take it back to the local sales agent. The two-year warranty gave them peace of mind as the product was sealed to prevent it being opened/ broken and was not designed for repair without the use of specialist tools. 


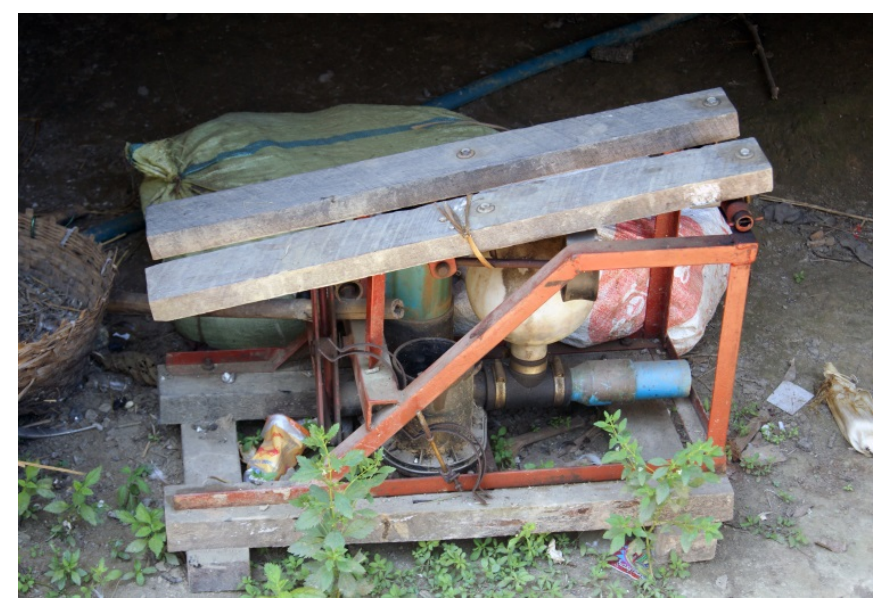

Figure 8. Abandoned agriculture water pump due to burs on the piston

These core insights highlight some of the differences in user perception, however, one key element was the desirability of the products. It was identified that although users were poor they did desire products which were aspirational. One user compared the d-light to other similar LED lights and stated that a key factor when deciding which they would buy they stated that the visual design was a fundamental factor.

\section{Advantages and disadvantages of local and global NPD}

These examples of local and global design and manufacture resulted in a number of challenges and opportunities for industrial designers. These have been summarised in Table 1:

\begin{tabular}{|c|c|c|}
\hline & Local NPD & Global NPD \\
\hline 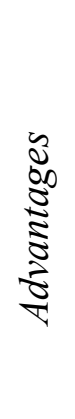 & 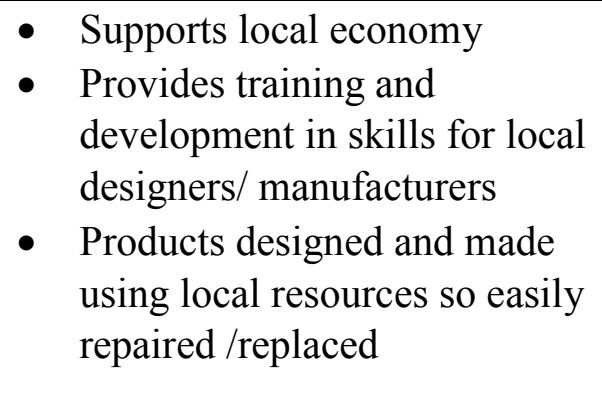 & $\begin{array}{l}\text { - Faster development process } \\
\text { where designers do not have } \\
\text { to spend so much time } \\
\text { teaching and instructing } \\
\text { manufacturers } \\
\text { - Higher levels of quality } \\
\text { control and availability of } \\
\text { materials }\end{array}$ \\
\hline
\end{tabular}




\begin{tabular}{|c|c|c|}
\hline & $\begin{array}{l}\text { Potential greater } \\
\text { understanding of market } \\
\text { needs through multinational } \\
\text { and multidisciplinary teams } \\
\text { - Can be aligned with } \\
\text { development goals for } \\
\text { charitable organisation }\end{array}$ & $\begin{array}{l}\text { Typically lower costs per unit } \\
\text { based on larger } \\
\text { manufacturing volumes } \\
\text { - Ability to incorporate } \\
\text { advanced functionality such } \\
\text { as electronics }\end{array}$ \\
\hline 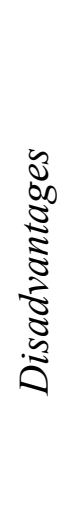 & $\begin{array}{l}\text { - } \begin{array}{l}\text { Limited skill level of local } \\
\text { population means product } \\
\text { development takes longer }\end{array} \\
\text { - } \quad \text { Limited availability of parts } \\
\text { and materials } \\
\text { - } \text { Increased time to market as } \\
\text { products typically designed } \\
\text { for batch production } \\
\text { - } \quad \text { Quality control can be an } \\
\text { issue. }\end{array}$ & $\begin{array}{l}\text { - Less direct access to market } \\
\text { and understanding of user } \\
\text { needs } \\
\text { - Access and availability of } \\
\text { spare/replacement parts can } \\
\text { be problematic } \\
\text { - Shipping and import tax } \\
\text { implications }\end{array}$ \\
\hline
\end{tabular}

Table 1. NPD approach - Advantages and Disadvantages

\section{Discussion}

This study in Myanmar highlighted the importance users placed on attributes to products. It was evident that users want to have well-made products with a contemporary appearance that were easy to use and affordable. There is also a demand for them to be fit for purpose and make a contribution to the social standing of the owner. These can be considered as being broadly similar to those for users in developed countries and highlight that a similar NPD process needs to be employed.

The social enterprise and LED light manufacturer both believed in adopting a user-centred design process which ensured that products met the needs of customers. This appears to be particularly important when designing for an unfamiliar user group. However, the issue of global or local design and manufacture had implications for product output, the NGO, the design team and the product users. For example, if the 
NPD process was carried out within the country of distribution, the NGO could better support the local economy, increase skills within the local population and help them to become more sustainable, thereby moving away from an NGO donation model.

However, this is a time-consuming process, creating a longer development process and often resulting in less durable/reliable product outcomes due to the lack of manufacturing skills and equipment. Access to materials also means that designers are unable to perform all of the required quality checks or identify the durability of a product. The result of this was evident where users neglected the product. Evidence of this was witnessed with the agricultural pump where a low quality manufacturing process had resulted in it not being used and left to rust under the house. It is therefore important that products designed and manufactured are of an appropriate quality to promote increased uptake and use. However, this does need to be set against the development aims the organisation has. If one of the aims the social enterprise is to support and develop the manufacturing sector then it is time-efficiency is less important, as long as the quality of the product is maintained.

Global NPD is characterised by a time-efficient development process as designers are not generally required to spend time explaining to manufacturers how to build the product. This can result in higher quality outputs that can incorporate advanced features such as electronics and solar power technology. However, the appeal of these products can be reduced by a lack of cultural understanding and limited availability of spare and replacement parts. The warranty scheme identified in this study appears to be a practical solution to this problem but is still dependent on the availability of sales agents and a mechanism for the return of products. 
The study has highlighted that there is a significant opportunity for industrial designers to play a critical role in assisting NGOs and manufacturers in creating desirable, high quality, long-lasting products which support local communities in LIEs. Understating the implications and differences of local and global manufacturing means that industrial designers are better equipped to create "products and systems that optimise function, value and appearance for the mutual benefit of both user and manufacturer" (IDSA, 2018).

\section{Conclusions}

Poverty and development are complex issues, with a significant number of initiatives failing to have the planned impact. The rise of design thinking, UCD and BoP economics have led to an increasing number of industrial designers creating products for these environments. However, despite these approaches, product solutions continue to fail to have a lasting impact. Methods to support designers are limited, and there is a general lack of understanding of the NPD process for designing and developing products for LIEs. To contribute new knowledge to the field of industrial design, this study identified that the design and development of products undertaken in developed countries could provide high-quality robust product solutions although this could be at the expense of user insight and does not always provide a long lasting and effective solution.

Supporting local design and manufacture is the ultimate aim of many NGO initiatives and designers. However, evidence suggests that, in some situations, this has resulted in inferior quality products which fail prematurely and are neglected by users. There is now an opportunity for industrial designers to play a leading role in this area by combining their skills in user centred design, manufacturing and design thinking to 
create product solutions which support the local economy while meeting the desires and needs of users.

\section{Further Research}

Further study is required to identify new methods and tools which could be created to allow designers to better support new product development at a local and global level.

\section{Acknowledgements}

I want to thank all those involved in the study, especially the social enterprise in Myanmar.

\section{References}

Austin-Breneman, J., \& Yang, M. (2013). Design for micro-enterprise: An approach to product design for emerging markets.

Castillo, L. C., Diehl, J. C., \& Brezet, J. C. (2012). Design considerations for base of the pyramid (BoP) projects.

Conklin, J. (2005). Dialogue mapping: Building shared understanding of wicked problems (1st ed.) John Wiley \& Sons.

Cagan, J. Vogel C.M. (2002). Creating Breakthrough Products: Innovation from product planning to program approval. Financial Times Prentices Hall

Diehl, J. C., \& Christiaans, H. H. C. M. (2007). The first learning experience of design for the BoP. Hong Kong: ISADR 07.

Donaldson, K. (2008). Why to wary of "design for developing countries". Ambidextrous, Spring, 35-37.

Easterly, W. (2007). Was development assistance a mistake? The American Economic Review, 97(2), 328-332.

Easterly, W. R. (2007). The white man's burden: Why the west's efforts to aid the rest have done so much ill and so little good. Oxford. Oxford University Press.

Gibbs, G. (2008). Analysing qualitative data: Qualitative research kit SAGE. 
Grundy, J., Annear, P., Ahmed, S., \& Biggs, B. (2014). Adapting to social and political transitions - the influence of history on health policy formation in the republic of the union of Myanmar (Burma). Social Science \& Medicine, 107(0). 179-188.

Hamner, S., Narayan, V., \& Donaldson, K. (2013). Designing for scale: Development of the ReMotion knee for global emerging markets. Annals of Biomedical Engineering, 41(9). 1851-1859.

Hennink, M. (2007). International focus group research: A handbook for the health and social sciences. Cambridge: Cambridge University Press.

IDEO. (2018). IDEO Human Centred Design Guide - Design Kit. Retrieved from https://www.ideo.com/post/design-kit

IDSA. (2018). Industrial Design Defined. Retrieved from https://www.idsa.org/news/dblog/what-id

Inhetveen, K. (2012). Transition challenges: Qualitative interviewing in a multi-lingual field. Qualitative Sociology Review, 8(2), 28-45.

Kandachar, P. (2012). Beyond design: Inclusive innovations and well-being. The Netherlands: Delft University of Technology.

MIT. (2013). Design for extreme affordability. Retrieved from http://extreme.stanford.edu/

Oevermann, U. (2008). Zur differenz von praktischem und methodischem verstehen in der ethnologischen feldforschung. In K. Inhetveen (Ed.), Translation challenges: Qualitative interviewing in a multi-lingual field (2012th ed., pp. 145-233)

Polak, P. (2008). Out of poverty: What works when traditional approaches fail (First Edition ed.). San Francisco: Berrett-Koehler Publishers.

Polak, P., \& Warwick, M. (2013). The business solution to poverty. San Francisco: Berrett-Koehler Publishers.

Prahalad, C. K. (2006). The fortune at the bottom of the pyramid - eradicating poverty through profits. New Jersey: Wharton School Publishing.

Robson, C., 1935-. (2011). Real world research : A resource for users of social research methods in applied settings. Chichester: Chichester : Wiley.

Sachs, J. D. (2005). Can extreme poverty be eliminated? Scientific American, 293(3), 56-65.

Schumacher, E. F. (1973). Small is beautiful - A study of economics as if people mattered (First ed.). London: Blond \& Briggs Ltd. 
Tesch, R. (1990). Qualitative Research: Analysis types and software tools. London: Falmer.

UNDP. (2011). International human development indicators. Retrieved from http://hdr.undp.org/en/data/map/

World Bank. (2011). What is a developing country? Retrieved from http://web.worldbank.org/WBSITE/EXTERNAL/EXTSITETOOLS/0,,contentM DK:20147486 menuPK:344190 pagePK:98400 piPK:98424 theSitePK:95474 ,00.html

World Bank. (2017). World Bank in Myanmar. Retrieved from https://www.worldbank.org/en/country/myanmar 